\title{
School Selection and the Social \\ Class Divide: How Tracking \\ Contributes to the Reproduction of Inequalities
}

Personality and Social

Psychology Bulletin

2019, Vol. 45(3) 477-490

(C) 2018 by the Society for Personality and Social Psychology, Inc

Article reuse guidelines:

sagepub.com/journals-permissions DOI: $10.1|77 / 0| 46|6721879| 804$ journals.sagepub.com/home/pspb (S)AGE

\author{
Anatolia Batruch', Frédérique Autin', \\ Fabienne Bataillard', and Fabrizio Butera'
}

\begin{abstract}
Selection practices in education, such as tracking, may represent a structural obstacle that contributes to the social class achievement gap. We hypothesized that school's function of selection leads evaluators to reproduce social inequalities in tracking decisions, even when performance is equal. In two studies, participants (students playing the role of teachers, $N=$ 99, or preservice and in-service teachers, $N=70$ ) decided which school track was suitable for a pupil whose socioeconomic status (SES) was manipulated. Although pupils' achievement was identical, participants considered a lower track more suitable for lower SES than higher SES pupils, and the higher track more suitable for higher SES than lower SES pupils. A third study $(N=160)$ revealed that when the selection function of school was salient, rather than its educational function, the gap in tracking between social classes was larger. The selection function of tracking appears to encourage evaluators to artificially create social class inequalities.
\end{abstract}

\author{
Keywords \\ social class inequalities, achievement gap, selection practices, tracking, teacher
}

Received January 16, 2018; revision accepted June 7, 2018

Students from disadvantaged social classes are consistently underrepresented in higher education in all industrialized countries (Organisation for Economic Co-operation and Development [OECD], 2011). The present research addresses social class inequalities in education by adopting an approach that considers how societal structures shape individual experience (Adams, Biernat, Branscombe, Crandall, \& Wrightsman, 2008; Kraus \& Park, 2017; Markus \& Stephens, 2017; Smeding, Darnon, Souchal, Toczeck-Capelle, \& Butera, 2013). In particular, we study the educational practice of tracking-grouping students based on their achievement level - which is in use in most OECD countries (OECD, 2013). Tracking is traditionally used because "a good fit between a student's ability and the level of instruction is believed to maximize the efficiency and effectiveness of the instructional process" (Hallinan, 1994, p. 79), but research has shown that tracking is linked to increased social class inequalities in educational attainment and earnings (e.g., Brunello \& Checchi, 2007). Drawing on research in social psychology and sociology of education that depicted the educational system as a contributor to the reproduction of social classes (Bourdieu \& Passeron, 1990; Stephens, Fryberg,
Markus, Johnson, \& Covarrubias, 2012), we contend that tracking is a structural obstacle that contributes to actively exclude lower social class pupils from higher education. In particular, we propose that tracking shapes the decisions of evaluators in a way that reproduces social class inequalities, even when achievement is equivalent, because it epitomizes a specific aspect of the educational system: its function of selecting the most deserving students.

Social psychology has recently produced a number of studies that experimentally manipulate the cultural and structural factors that might affect the results of students from different social classes (Goudeau, Autin, \& Croizet, 2017). Here, we present the first experimental investigation of the impact of students' social class on tracking decisions of evaluators.

'Université de Lausanne, Switzerland

Corresponding Author:

Fabrizio Butera, Université de Lausanne, IP-SSP, Géopolis, CH 1015, Lausanne, Switzerland.

Email: fabrizio.butera@unil.ch 


\section{Tracking as Selection}

The practice of grouping students by achievement levels into differentiated curricula can be found in all OECD countries (OECD, 2013). Some countries, such as Austria, Germany, Hungary, the Czech Republic, and Switzerland, track students into separate academic/vocational programs or schools for their full curriculum (i.e., full-curriculum tracking). This separation has lasting consequences, as students in the lower tracks are not allowed to directly access higher education. Other countries (e.g., the United States, Australia, Canada, the United Kingdom, and New Zealand) practice various forms of within-school "ability grouping/ streaming" or "course-by-course tracking" in their curriculum (Chmielewski, 2014). In this case, students are tracked for certain courses, not programs, and every student is presumably eligible to go to University. Students are usually tracked (into courses, programs, or schools) during secondary schools at the age of 15 or 16 years. Nonetheless, early tracking (10-12 years old) occurs in European countries such as Germany, Austria, Switzerland, Belgium, and the Netherlands (OECD, 2013).

Several authors have noted that tracking systems should be described in terms of degree of selection (countries/ schools have a more or less restrictive tracking system), rather than consider tracking as a binary variable (tracking vs. no tracking; Bol, Witschge, Van de Werfhorst, \& Dronkers, 2014; Chmielewski, 2014). Despite the above differences in application, these selection practices (tracking and ability grouping) have been argued to fulfill the same function, namely, differentiating students by achievement levels and tailoring the curriculum to fit students' academic needs and abilities (Chmielewski, 2014).

\section{Tracking and Learning}

However, the support for school tracking has been controversial. The arguments put forward in the controversy often revolve around a perceived trade-off between efficiency and equality, as educational systems aim for both a high level of achievement and equality of opportunities (Felouzis \& Charmillot, 2013). Those who favor tracking have argued that homogeneous classes contribute to a more focused curriculum, leading to an optimal learning context for all students (Hallinan, 1994). Others argue against tracking because in heterogeneous classes weaker students profit from the presence of stronger students, without hindering the latter's performance (Kerckhoff, 1986), or even favoring it (Konan, Chatard, Selimbegović, \& Mugny, 2010).

Empirical findings on the benefits of tracking on mean performance have been mixed. Whereas there is some evidence that the effects of tracking can be slightly beneficial for high-ability groups and detrimental for low-ability groups (Hattie, 2002; Huang, 2009), cross-national studies suggest that the overall impact of tracking on student performance is very small and most often negative (Betts \& Shkolnik, 2000; Hattie, 2002; Huang, 2009). Consequently, some authors question the existence of the potential trade-off between efficiency and equality, as the evidence for an increase in performance is limited, yet the impact on the achievement gap between students of different levels is more robust (Schütz, Ursprung, \& Wößmann, 2008; Van de Werfhorst \& Mijs, 2010).

\section{Tracking and Social Inequalities}

Indeed, students' social background has been shown to yield a greater influence on students' chance of success in countries that practice tracking than in countries with comprehensive school systems (Brunello \& Checchi, 2007; Chmielewski, 2014; Hanushek \& Wößmann, 2006; Schütz et al., 2008). Even when tracking is not operationalized as a binary variable but as a scale taking into account the age of first selection, the length of the tracked curriculum, and number of tracks, results show that an achievement gap due to the students' socioeconomic background is larger in educational systems that are strongly tracked compared with more comprehensive systems (Van de Werfhorst \& Mijs, 2010). Another study carried out with schools using academic/vocational tracking and schools using "ability grouping" concluded that they display rather similar achievement gaps due to students' socioeconomic status (SES; Chmielewski, 2014). In sum, international surveys suggest that the implementation of selection practices of various forms can impact the actual distribution of opportunities across social classes.

\section{The Structure of Educational Institutions and the Social Class Achievement Gap}

We contend that tracking is not just a device that allows the educational system to sort students as a function of their objective performance, but that it is a practice that paradoxically perpetuates existing social class inequalities. This contention builds on sociopsychological and sociological analyses of the role of educational institutions in reproducing social inequalities. In sociology of education, Bourdieu and Passeron (1990) argued that the school system is in some measure an active contributor to the social class achievement gap because it is structured and organized by the upper class culture. Using an experimental approach, research in social psychology has provided evidence for the causal role of educational settings (e.g., institutional norms, classroom settings, and educational practices) in restraining the success of lower social class students (Batruch, Autin, \& Butera, 2017; Croizet, Goudeau, Marot, \& Millet, 2017; Smeding et al., 2013). The literature on cultural mismatch demonstrated that the middle/upper class norms and values promoted by higher education institutions interfere with the achievement of 
first-generation students (who are the first members of the family who go to college; Stephens et al., 2012). Moreover, the literature on stereotype threat suggests that the evaluative situations put in practice in universities produce a fear to confirm negative stereotypes among lower status students, which contributes to the academic difficulties experienced by low social class students (Croizet \& Claire, 1998; Croizet $\&$ Millet, 2012). Recently, a set of experiments showed that making social comparison salient can be detrimental for the performance of working-class pupils. When pupils were asked to raise their hand upon finishing with a task, the performance of lower social class pupils decreased (Goudeau \& Croizet, 2017). These studies indicate that the structure of the educational system can shape students' behavior and achievement, but we suggest that it could also shape the behavior of the agents implementing its institutional practices, notably teachers.

\section{Evaluators' Decisions and Inequalities}

It has long been proposed that teachers can affect student experience by holding biased beliefs and differential expectations of students (Dusek \& Joseph, 1983; Riegle-Crumb \& Humphries, 2012). Indeed, several studies have provided empirical support for discrimination based on factors such as nationality, gender, race, or even SES in school contexts (Farkas, 2003; Hinnerich, Höglin, \& Johannesson, 2015; Kiss, 2013). Regarding tracking, teachers are less likely to promote students with an immigrant background than native students to a higher track (Glock, Krolak-Schwerdt, Klapproth, \& Böhmer, 2013). The results of studies on teachers' discrimination have largely been interpreted as documenting biases in individuals. We rather contend that discrimination in tracking could be the by-product of the institutional logic underlying the implementation of selective practices. Let us see why.

\section{The Two Functions of Educational Institutions}

The ongoing debate over tracking policies, between efficiency and equality, occurs at two different levels: educational and societal. Previous authors noted that the potential trade-off of tracking might not reside on its beneficial effect on student's performance but rather on its efficiency to provide the labor market with differentially skilled workers (Bol \& Van de Werfhorst, 2013). More generally, this debate reflects the ambivalence between two functions assigned to the school system: the educational function and the function of selection (Autin, Batruch, \& Butera, 2015, in press; Darnon, Dompnier, Delmas, Pulfrey, \& Butera, 2009; Jury, Smeding, \& Darnon, 2015). Since the development of compulsory education, the school system has been required to pursue democratic objectives and provide education to all pupils by transmitting knowledge, skills, and culture. In this regard, the school system fulfills an educational function.
Nonetheless, the educational system is also expected to prepare students for their future positions in the social hierarchy (Darnon et al., 2009; Dornbusch, Glasgow, \& Lin, 1996). The certifications of competence (i.e., grades or diplomas) awarded by the educational institutions are used to compare and rank students to determine which are worthy of following the most prestigious paths, thereby fulfilling the function of selection of the educational system.

Previous studies in social psychology have found that the function of selection could have detrimental effects on the performance of low-SES students. A study demonstrated that when academic assessment was presented to students as fulfilling a selective rather than an educational purpose, the achievement gap between low- and high-SES students was higher (Smeding et al., 2013). The mere activation of the function of selection of the university system has been shown to impair the performance of first-generation students compared with continuing-generation students (i.e., one or both parents finished high school; Jury et al., 2015). These studies conclude that the mechanism responsible for the impairment of performance is rooted in the structural functioning of the institution (i.e., its function of selection).

\section{The Present Research}

In the present research, we move beyond the study of how low-SES students underperform in a selective environment and investigate the active involvement of selection in education: We propose to study the link between the function of selection and the social class achievement gap from the perspective of the evaluators, to test whether a selective institutional context can lead evaluators to create the difficulties/ advantages encountered by students of different social classes. Importantly, in this study, we experimentally manipulate the pupils' SES, but we keep the pupils' performance constant to overcome the limitations of previous correlational studies, which could not conclude on causality in the relationship between tracking, SES, and past performance.

In the case of selection practices such as tracking, decisions are meant to be primarily based on prior achievement, which is believed to be a fair reflection of the student's individual merit. This ideology, meritocracy, proposes that only individual inputs should be considered, and group-based considerations ignored, to determine one's social position (Sabbagh, Resh, Mor, \& Vanhuysse, 2006). Paradoxically, even though meritocracy as a justice principle is perceived as being relatively bias-free (Son Hing et al., 2011), research has shown that meritocratic principles can have the opposite psychological effects. For instance, studies conducted by Son Hing, Bobocel, and Zanna (2002) have shown that endorsement of the merit principle was associated with increased opposition to policies challenging the status quo in favor of disadvantaged group members. Meritocracy is often used as a justification to oppose affirmative action (Faniko, Lorenzi-Cioldi, Buschini, \& Chatard, 2012). In the field of 
education, Darnon, Smeding, and Redersdorff (2018) showed that beliefs in school meritocracy were negatively associated with interest or behavioral intention to implement an equalizing pedagogical method. Taking the perspective of evaluators, another study showed that an organizational culture emphasizing meritocratic principles led managers to favor men over equally competent women (Castilla \& Benard, 2010).

Contrary to the function of selection that can be linked to a meritocratic principle, the educational function seems to be related to an egalitarian principle as it aims at equalizing individuals' level of instruction. Egalitarian principles have been associated with positive outcomes for disadvantaged group members. For instance, in an engineering college, implementing egalitarian social norms led to stronger intentions to speak out against racist behaviors, and more positive attitudes toward diversity in engineering (Bennett \& Sekaquaptewa, 2014).

In light of these results, we propose that merit-based selective practices, like tracking, are structural contexts that encourage agents of the educational system, namely, teachers, to maintain status inequalities between pupils of advantaged and disadvantaged social background, even when achievement is equal. Conversely, focusing agents on the educational function of the educational system could reduce such a tendency to maintain status inequalities.

\section{Hypotheses and Overview}

We tested the hypothesis that tracking decisions will be influenced by the evaluators' awareness of the pupils' SES, even if pupils' achievement is kept identical and will result in considering a lower track more suitable for a low-SES pupil than for a high-SES pupil, and the reverse for a higher track (Hypothesis 1). Two experiments tested this hypothesis, one with university students playing the role of teachers, and another with preservice and in-service teachers. Furthermore, a third experiment tested that, if it is true that such discriminatory behavior in tracking judgments is to some extent the result of an institutional logic of selection, rather than purely individual prejudice, then the social class gap in tracking decisions will be stronger when the educational system's function is portrayed as being selective rather than educational (Hypothesis 2).

\section{Experiment I}

\section{Method}

Participants. A total of 104 psychology students enrolled in a French-speaking Swiss university participated in this study in exchange for partial credit. A sensitivity analysis on $\mathrm{G}^{*}$ Power using a negative correlation between the tracking measures $(r=-.50)$ and an $80 \%$ power returned a required effect size of $f=.24$, Cohen's $d=0.48$ for the expected interaction between track and pupil's SES (Faul, Erdfelder, Buchner, \& Lang, 2009). All participants have been randomly assigned to one of the four between-participants experimental conditions: target's SES (low vs. high) $\times$ target's Gender (girl vs. boy). The target's gender was included as a control variable. Data from five participants were excluded because they were suspicious of the aim of the study (final sample: $N=99,85$ women, 14 men, $M_{\text {age }}=$ 21.43, $S D_{\text {age }}=2.53$ ).

Material and procedure. Switzerland is a federal state, divided in relatively autonomous cantons (like in Germany or the United States); in most cantons, performance (grades) at age 12 determines whether a pupil will follow a vocational or academic track (i.e., different curricular programs). Some schools allow for borderline cases (i.e., pupils whose grades are above the passing grade but only slightly below the usual requirements for the highest track) to be reviewed by teachers and the school director, to decide whether the pupil should be allowed to pursue the academic track (an average of $40 \%$ of pupils enter the academic track). For the present study, participants were asked to take the role of a teacher in this context and help decide which secondary school track was most suitable for a particular borderline case (the target pupil). Participants received a booklet ${ }^{1}$ informing them about (a) the future consequences of sending the pupils to the higher or lower track (e.g., higher track: leading to high school and university, lower track: leading to an apprenticeship or general knowledge schools), (b) the grade requirements for tracks, and (c) the target's description including the pupil file (similar to the one actually in use), grades, and a brief description of his or her extracurricular activities. Relevant information about the target's SES and gender were presented among neutral information (e.g., date of birth, address, nationality - all targets were presented as native pupils).

Manipulation of target's SES and gender. Gender was manipulated by changing the pupil's first name and the reported gender in the pupil file. SES was manipulated by altering the pupil's first name (using stereotypical names of high vs. low social class girls and boys: "Charlotte/Louis" vs. "Cindy/ Bryan"; cf., Coulmont, 2011), parental occupation (mother: director of marketing vs. waitress; father: architect vs. construction workman), and extracurricular activities (e.g., traveling to London vs. local amusement park). Importantly, every target was presented with the same grades.

Measures of suitability of school tracks. We included two sets of measures ${ }^{2}$ to estimate what participants thought was the appropriate track for the bogus pupil. Participants were to evaluate separately on 7-point scales the suitability of each track for the target (from $1=$ totally disagree to $7=$ totally agree), once according to their own opinion as a teacher and again according to what they thought other teachers' opinion was (supposedly included in the decision). The first two 


\section{Lower Track}

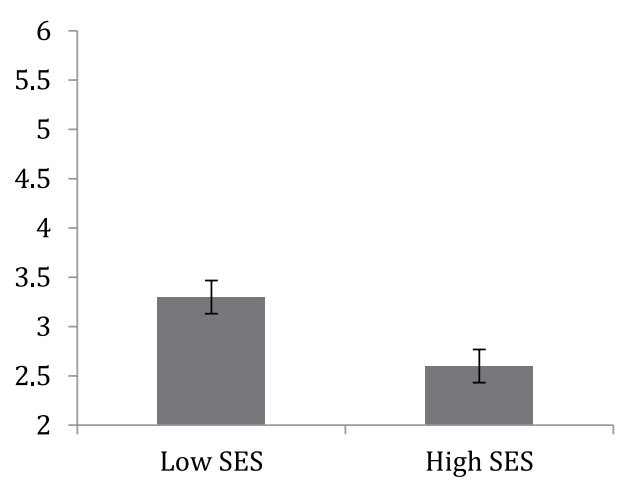

Higher Track

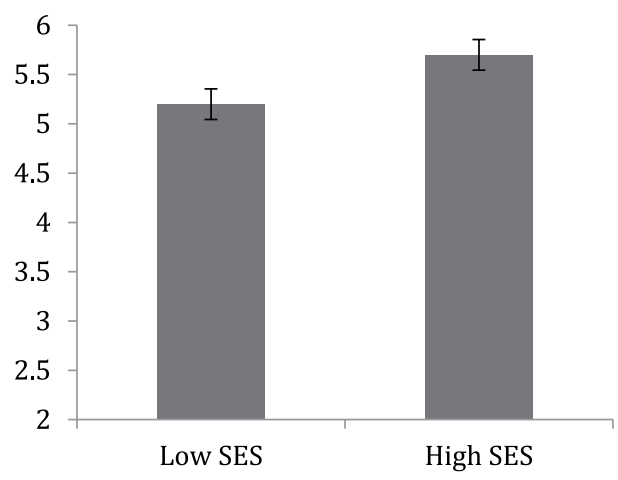

Figure I. Mean suitability from the participants' point of view of lower and higher secondary school tracks as a function of target's SES in Experiment $\mathrm{I}$.

Note. Error bars represent standard errors of the mean. SES = socioeconomic status.

measures (i.e., "In your opinion, to what extent the pupil should be sent to the lower/higher track?") were meant as an indicator of the participants' own decision, were they to be in this position. We included the two other measures to investigate participant's perception of the school system functioning (i.e., "In your opinion, to what extent the other teachers making the decision would send the pupil to the lower/higher track?"; the analyses on these measures are presented in the Supplemental Materials).

The questionnaire ended with a manipulation check to make sure that participants had correctly perceived the target's background - participants were asked to recall information about the pupil they had seen and were told to report on a 7-point scale to what extent the pupil seemed to come from a highly disadvantaged (1) versus highly advantaged (7) background - and sociodemographic questions, among which information pertaining to the participants' parental level of education and employment. Finally, participants were thanked and debriefed.

\section{Results}

Manipulation check. We analyzed the rating of the perceived socioeconomic background of the target in a 2 (target's gender: girl vs. boy) $\times 2$ (target's SES: high vs. low) ANOVA. As expected, we found an effect of the target's SES indicating that low-SES targets were perceived as coming from a less-advantaged background $(M=3.88, S D=0.94,95 \%$ confidence interval $[\mathrm{CI}]=[3.65,4.10])$ than high-SES targets $(M=5.96, S D=0.61,95 \% \mathrm{CI}=[5.74,6.19]), F(1$, $95)=169.11, p<.001, \eta_{\mathrm{p}}^{2}=.64$, Cohen's $d=2.62$. No other effects reached significance $\left(F_{\mathrm{S}}<1\right)$.

Suitability of school tracks. We examined the participants' assessment of the suitability of each track in a 2 (target's gender: girl vs. boy) $\times 2$ (target's SES: high vs. low) $\times 2$ (track: high vs. low) mixed ANOVA with the last factor as repeated measures. The analysis revealed no main effect of target's SES, $F(1,95)=1.74, p=.19, \eta_{\mathrm{p}}^{2}=.02$, and a main effect of track, $F(1,95)=149.47, p<.001, \eta_{\mathrm{p}}^{2}=.61$, indicating that participants considered the higher track $(M=5.42$, $S D=1.11,95 \% \mathrm{CI}=[5.22,5.65])$ to be more suitable for all targets than the lower track $(M=2.92, S D=1.23,95 \%$ $\mathrm{CI}=[2.68,3.14])$. This main effect was qualified by the predicted interaction between track and target's SES, $F(1,95)=9.14, p=.003, \eta_{\mathrm{p}}^{2}=.09$. As depicted in Figure 1, the lower track was deemed more suitable for the low-SES target $(M=3.28, S D=1.29,95 \% \mathrm{CI}=[2.95,3.61])$ than for the high-SES target $(M=2.54, S D=1.06,95 \% \mathrm{CI}=$ $[2.21,2.87]), F(1,95)=10.09, p=.002, \eta_{\mathrm{p}}^{2}=.10$, Cohen's $d=0.6$. Symmetrically, the higher track was considered by participants to be more suitable when the target's SES was high $(M=5.69, S D=1.02,95 \% \mathrm{CI}=[5.38,5.99])$ than when it was low $(M=5.18, S D=1.15,95 \% \mathrm{CI}=[4.88$, $5.48]), F(1,95)=5.43, p=.02, \eta_{\mathrm{p}}^{2}=.05$, Cohen's $d=0.5$.

Target's gender was initially included as a control variable and the results indicated no significant main effect of gender, or interaction between gender and $\operatorname{SES}(F \mathrm{~s}<1$; ps $>$ .71). However, the analysis revealed an unexpected gender by track interaction, $F(1,95)=9.13, p=.003, \eta_{\mathrm{p}}^{2}=.09$, that was further qualified by an unexpected three-way interaction between track, target's SES, and gender, $F(1,95)=$ $6.31, p=.01, \eta_{\mathrm{p}}^{2}=.06$. The interaction indicated that the difference between high- and low-SES was not significant for the female targets in either track $\left(F_{S}<1\right)$, whereas it was significant for the male targets on the assessment of both the lower track, $F(1,95)=14.87, p<.001, \eta_{\mathrm{p}}^{2}=.14$, and the higher track, $F(1,95)=10.13, p=.002, \eta_{p}^{2}=.10$.

Participants' background. One might argue that the participant's own social class may have an impact on their tracking judgment, under the form of an in-group bias. Participants 
were considered as first-generation (e.g., none of the parents has a university degree) or continuing-generation (e.g., at least one parent has a university degree), following the procedure used in many social psychology studies on social class in educational context (Sirin, 2005; Snibbe \& Markus, 2005; Stephens et al., 2012).

We performed a 2 (participant's generation: first vs. continuing-generation) $\times 2$ (target's gender: girl vs. boy) $\times$ 2 (target's SES: high vs. low) $\times 2$ (track: high vs. low) ANOVA with the last factor as repeated measures. The analysis showed an effect of track, $F(1,90)=148.91, p<$ $.001, \eta_{\mathrm{p}}^{2}=.62$, and the predicted and above-documented Target's SES $\times$ Track interaction, $F(1,90)=7.03, p=.009$, $\eta_{\mathrm{p}}^{2}=.07$. Participants' generation did not interact either with track, $F(1,90)=2.52, p=.12, \eta_{\mathrm{p}}^{2}=.03$, or with any other variables $\left(F_{\mathrm{S}}<1.67\right)$.

\section{Discussion}

We designed this first experiment to examine whether individuals acting as agents of the educational system would reproduce existing social disparities when placed in the strategic position of having to actively influence pupils' prospects, namely, when asked to make a tracking decision. Results showed that pupils' SES was an influential factor in conceding academic opportunities. Although grades were the same for all targets, participants imagined that as teachers they would consider a lower track more suitable for a lowSES pupil when compared with a high-SES pupil, and reciprocally a higher track more suitable for a high-SES pupil than for a low-SES pupil.

To preserve the ecological validity of the study, the scenario was made to resemble actual tracking dilemmas in the Swiss system where teachers and the principal can offer a second chance to pupils who are borderline cases for the higher track (i.e., slightly below official standards). This specific characteristic is important for the interpretation of the effect, as most research in the discrimination literature focuses on targets from disadvantaged groups who meet the official criteria for an opportunity (e.g., for a job application) but are less likely to benefit from it in comparison with targets from advantaged groups (Quillian, Pager, Hexel, \& Midtbøen, 2017). Allowing students who do not meet the criteria to follow an academic path, on the contrary, could be interpreted as offering these students a privilege. In the case of this study, this privilege appears to be more readily offered to high-SES students than to low-SES students. This result is consistent with the theorizing of researchers such as DiTomaso (2015) who suggest that the reproduction of inequalities is also a by-product of favoritism processes, where advantaged group members are extended the benefit of the doubt in case of mistakes and might be rewarded for promise over performance.

We also observed that the effects were stronger for male than for female targets. This unexpected effect might be linked to different attributions to academic success depending on gender. According to Fennema, Peterson, Carpenter, and Lubinski (1990), teachers perceive boys' performance as being more related to essential qualities such as abilities, whereas girls' performance are seen as being more the results of effort. In the case of girls, it may be that the impact of the target's SES was reduced by the gender-based assumption regarding the effort involved in the academic path. However, this effect might also be explained by the fact that at this level of education, girls tend to generally outperform boys academically in many countries (OECD, 2011), and some research suggests that teachers and young children perceive behavioral and academic stereotypes in early education as being more favorable toward girls than boys (Hartley \& Sutton, 2013; Jones \& Myhill, 2004). Indeed, prior experimental work suggested that stereotypical boys are seen by teachers as less academically engaged when compared with nonstereotypical boys and girls (Heyder \& Kessels, 2015). Although this effect of gender should be replicated before reaching any definitive conclusion, we think it possible that the advantages/disadvantages of girls' SES could be less impactful for school decisions if their performance is seen as being more linked to efforts and if girls are seen by teachers as less of an academic risk.

\section{Experiment 2}

To ensure that the above results were not biased by participant's lack of teaching and selecting experience, we conducted a replication with a sample of preservice and in-service teachers.

\section{Method}

Participants. Based on the observed effect size and the correlation between the tracking measures in Experiment 1 $\left(\eta_{\mathrm{p}}^{2}=.09, r=-.70\right)$, an a priori analysis using SPSS effect size in $\mathrm{G}^{*}$ Power revealed a minimum sample size of 70 for $80 \%$ power to detect the predicted within-between interaction (track $\times$ target's SES). A first sample of practicing and preservice teachers enrolled in a master's class in a teachers' college took part to the study ( $N=36,34$ practicing teachers and two preservice teachers). A second sample of practicing teachers was recruited by one of their colleagues $(N=54)$. In the second sample, only the male target conditions were presented so we decided to exclude the participants from the first sample who saw the female targets $(N=20)$. However, preliminary analyses were performed with both samples and we found similar results (see Supplemental Materials). The final sample consisted of 70 teachers $\left(M_{\text {age }}=38.46, S D=\right.$ 10.50 ; 53 women, 15 men, and two unspecified). Their mean teaching experience was 11.71 years $(S D=9.77)$.

Material and procedure. The descriptions of the target and the general procedure were identical to those used in Experiment 


\section{Lower Track}

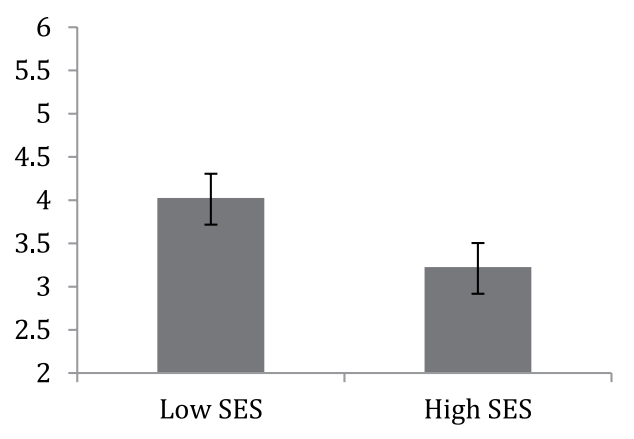

Higher Track

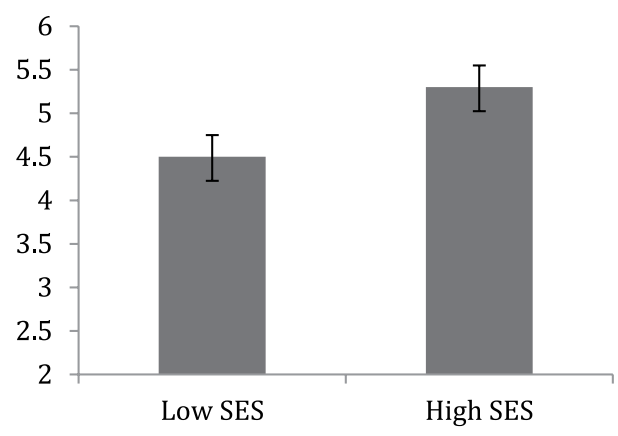

Figure 2. Mean suitability from the participants' point of view of lower and higher secondary school tracks as a function of target's SES in Experiment 2.

Note. Error bars represent standard errors of the mean. SES = socioeconomic status.

1. The cover story was however adapted to fit with our sample. The study was presented as a comparison between individual and collective expert decision-making processes. All participants were told they were to answer individually and were asked to decide which track was most suitable for a borderline pupil (i.e., whose grades are just below the usual requirement to be tracked in the higher track). As agents of the Swiss school system, teachers are familiar with tracking decisions, but they received nonetheless the booklet informing them about the outcomes of tracking for pupils. They read the administrative file presenting the pupil's SES and grades and were then asked to indicate the suitability of each (low and high) track for the pupil. ${ }^{3}$ Finally, they reported demographic information including their gender, age, and number of years of teaching experience. At the end of the study, participants were thanked and debriefed.

\section{Results}

Manipulation checks. An ANOVA involving the target's SES (low vs. high) revealed that participants did indeed perceive the low-SES pupil $(M=3.73, S D=0.82,95 \% \mathrm{CI}=[3.49$, 3.99]) as being less advantaged than his high-SES counter$\operatorname{part}(M=6.00, S D=0.68,95 \% \mathrm{CI}=[5.73,6.28]), F(1,67)$ $=148.82, p<.001, \eta_{\mathrm{p}}^{2}=.69$, Cohen's $d=3.0$.

Suitability of school tracks. We performed a 2 (target's SES) $\times$ 2 (track) ANOVA with the last factor as a repeated measure. First, we observed no main effect of target's SES, $F<1$, $n s$, and a significant main effect of track, $F(1,68)=11.82$, $p=.001, \eta_{\mathrm{p}}^{2}=.15$. Participants considered the higher track $(M=4.91, S D=1.57,95 \% \mathrm{CI}=[4.54,5.27])$ to be more suitable for all targets than the lower track $(M=3.63$, $S D=1.74,95 \% \mathrm{CI}=[3.22,4.04])$. Moreover, as depicted in Figure 2, the predicted interaction between target's SES and track was significant, $F(1,68)=4.83, p=.03, \eta_{\mathrm{p}}^{2}=.07$. For the lower track, the low-SES target $(M=4.03, S D=1.90$,
$95 \% \mathrm{CI}=[3.48,4.57])$ was perceived as being marginally more suitable than the high-SES target $(M=3.22, S D=1.43$, $95 \% \mathrm{CI}=[2.61,3.83]), F(1,68)=3.79, p=.06, \eta_{\mathrm{p}}^{2}=.05$, Cohen's $d=0.5$, whereas for the higher track, the high-SES pupil $(M=5.32, S D=1.30,95 \% \mathrm{CI}=[4.78,5.87])$ was perceived as being more suitable than the low-SES pupil $(M=4.49, S D=1.68,95 \% \mathrm{CI}=[4.00,4.98]), F(1,68)=$ $5.17, p=.03, \eta_{\mathrm{p}}^{2}=.07$, Cohen's $d=0.6$. We thus replicated the results of Experiment 1 with a sample of teachers.

Teachers' experience (in years). To test whether the documented gap in personal assessment of track suitability was affected by participants' experience in teaching, we performed a regression analysis with the target's SES (low coded -0.5 , high coded 0.5 ), the teacher's experience (centered; $N=66$; four missing values), and the interaction as predictors of the difference score between the higher track and the lower track. Analyzing the difference score allows to include the within-participants "Track" factor in the analysis (Judd, McClelland, \& Ryan, 2011). The previously reported interaction between SES and track remained similar, $t(62)=$ $2.22, p=.03, \eta_{\mathrm{p}}^{2}=.07$, and was not further moderated by the teachers' experience $t(62)=-.18, p=.86, \eta_{\mathrm{p}}^{2}=.00$.

\section{Experiment 3}

Our hypothesis was that it is the selective role of educational institutions that drives the discriminatory behavior. In the two previous studies, the observed social class gap in tracking was affected neither by the respondent's social class nor by the extent of their actual practice as teachers. The third study aimed to test whether it is indeed a structural mechanism that drives the social class gap in tracking: If the observed behavior is driven by a compliance with the function of selection of the system, rather than an individual's propensity to discriminate, then manipulating such function (i.e., either to select or to educate) should impact the tracking 
decisions. We hypothesized that the gap between the targets in the tracking decision should be wider in the condition where the function of the school system is presented as being selection rather than education. We did not expect the effect of SES on tracking between the "education" condition and the "selection" condition to disappear because tracking in itself is a selective practice; therefore, using tracking with an educational mind-set might reduce the discriminatory behavior, but not completely eliminate it.

\section{Method}

Participants. The sample consisted of 160 first-year life science and technology students from a Swiss polytechnical university ( 82 women, 71 men, and seven unspecified; $\left.M_{\text {age }}=20.08, S D=1.19\right)$. An a priori analysis using the correlation between the tracking measures $(r=-.70)$ and the more conservative effect size observed in Experiment $2\left(\eta_{\mathrm{p}}^{2}=.07\right)$ returned a minimum of 128 participants to achieve an $80 \%$ power level to test a within-between interaction (2: tracks $\times 2$ : target's SES $\times 2$ : school's Function). Participants voluntarily and collectively took part in the study during a class. Participants were randomly assigned to one of the experimental condition in the school's function (education vs. selection) $\times$ target's SES (low vs. high) $\times$ target's gender (boy vs. girl) between-participants design. As in Experiment 1, target's gender was used as a control variable.

Material and procedure. Participants were presented with the same scenario, in which they were asked to imagine they were teachers, and the same targets used in Experiment 1. Again, all targets were presented as having the same grades, which were slightly below the usual requirement for the higher track. Participants were also informed of the consequences of tracking (i.e., possibility for the student to pursue postsecondary education or not).

Manipulation of school's function. Before seeing the information about the target's case and the implications of tracking, participants read a paragraph about the characteristics of the Swiss school system, which served to render the function of the educational system (selection vs. educational) salient. In the educational function paragraph, the main goal of the educational system was described as imparting all students with knowledge and skills and to help everyone develop their competence. In the selection function paragraph, the main goal of the educational system was described as identifying and rewarding the most deserving students. For instance, in the educational function condition, they were told that the Swiss school system's goal was "to develop skills and give students the opportunity to progress in the mastery of their knowledge." In the function of selection condition, the school's goal was "to orient students according to academic abilities and lead everyone to the maximum of their potential."

\section{Results}

Manipulation checks. A 2 (target's SES) $\times 2$ (target's gender) $\times 2$ (school's function) ANOVA was conducted to analyze participants' perception of the target's SES. The results showed a marginal effect of target's gender, $F(1,152)=$ $3.52, p=.06, \eta_{\mathrm{p}}^{2}=.02$, and confirmed that participants estimated that the low-SES target came from a less-advantaged background $(M=3.67, S D=0.91)$ than the high-SES target $(M=5.55, S D=0.73), F(1,156)=207.49, p<.001$, $\eta_{\mathrm{p}}^{2}=.58$, Cohen's $d=2.3$ ). No other effects were significant $(p s<.22)$.

We included a manipulation check to ensure that participants had correctly perceived the school system as being selective or educational. The vast majority ( $78 \%$ of participants - that is, 128) answered correctly. We tested our final model with samples including and excluding those participants and we found similar results. We decided to keep the full sample.

Suitability of school tracks. ${ }^{4}$ Given the specific direction of the expected results, we recoded the experimental conditions into three orthogonal contrasts (Judd \& McClelland, 1989): the planned contrast testing our hypothesis (coded: $+1,-1$, $+3 ;-3$, respectively, for the high SES/education, low SES/ education, high SES/selection, and low SES/selection conditions), and two orthogonal contrasts testing the remaining variance $(+1,+1,-1,-1$ and $-3,+3,+1,-1)$. The planned contrast predicts that the means are linearly ordered in the following direction: For the higher track, the high-SES pupil should be considered the most suitable in the selection condition, followed by the high-SES pupil in the educational condition, next the low-SES pupil in the educational condition, and finally the low-SES pupil in the selection condition. If the data support our hypothesis, the first contrast should be significant, but not the others (Brauer \& McClelland, 2005; Judd \& McClelland, 1989).

It is worth noting that the social class gap is in opposite directions in the two tracks: For the lower track, the highSES pupil should be considered the least suitable in the selection condition, followed by the high-SES pupil in the educational condition, next the low-SES pupil in the educational condition, and finally the low-SES pupil in the selection condition. We thus expected an interaction between the track and the contrast. The suitability of tracks was analyzed with the contrast-coded conditions as a between-participants factor and the tracks (higher vs. lower) as a repeated measure. The target's gender was originally included in the analysis, but as it did not result in any significant main or interaction effects, we did not include the variable in the final model. The analysis showed no main effect of the contrast-coded conditions, $F \mathrm{~s}<1, n s$, and a main effect of track, $F(1,156)=103.63, p<.001, \eta_{\mathrm{p}}^{2}=.40$, revealing that participants found the higher track $(M=5.23, S D=$ $1.52,95 \% \mathrm{CI}=[5.00,5.45])$ to be more suitable for all 
Lower Track

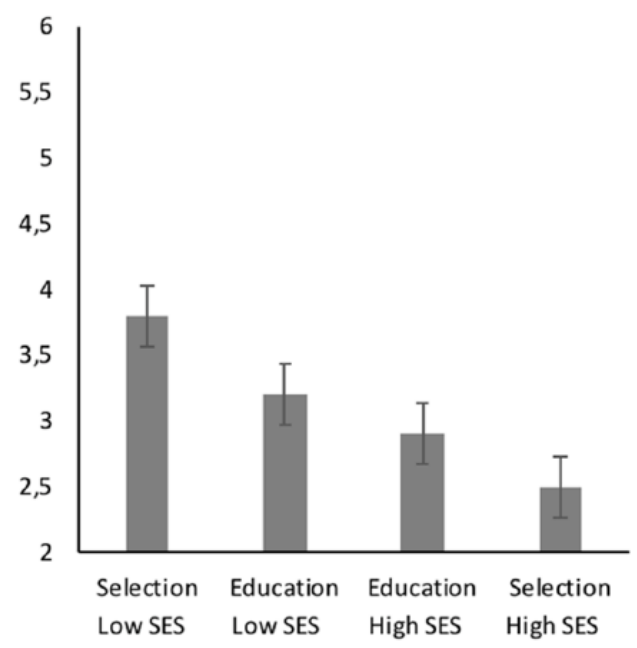

Higher Track

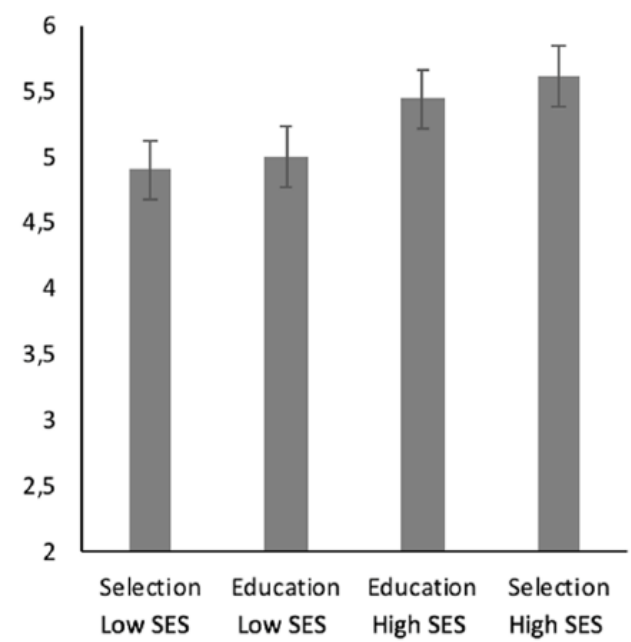

Figure 3. Mean suitability from the participants' point of view of lower and higher secondary school tracks as a function of target's SES and school's function in Experiment 3.

Note. Error bars represent standard errors of the mean. SES = socioeconomic status.

targets than the lower track $(M=3.09, S D=1.45,95 \% \mathrm{CI}$ $=[2.86,3.32])$. We found the expected significant interaction between track and the planned contrast, $F(1,156)=$ $11.25, p=.001, \eta_{\mathrm{p}}^{2}=.06$. The two contrasts testing the residual variance did not interact with track, $F_{S}<1$.

The interaction between track and the planned contrast, shown in Figure 3, was further decomposed by track. In both the lower and the higher track, the linear planned contrast was significant, $F(1,156)=11.69, p=.001, \eta_{\mathrm{p}}^{2}=.07$ and $F(1,156)=7.22, p=.008, \eta_{\mathrm{p}}^{2}=.04$, while the residual contrasts were not, $F_{S}<1$, thereby indicating a linear effect. For the lower track, and as expected, the high-SES target in the selection condition $(M=2.54, S D=1.39$, $95 \% \mathrm{CI}=[2.07,3.01])$ was considered the least suitable, followed by the high-SES target in the educational condition $(M=2.88, S D=1.41,95 \% \mathrm{CI}=[2.42,3.33])$, the lowSES target in the educational condition $(M=3.39, S D=$ $1.49,95 \% \mathrm{CI}=[2.92,3.85])$, and finally the low-SES student in the selection condition $(M=3.56, S D=1.59,95 \%$ $\mathrm{CI}=[3.11,4.02])$. The effect size of the difference between high- and low-SES targets (the SES gap) was Cohen's $d=$ 0.7 in the selection condition, and Cohen's $d=0.3$ in the educational condition. For the higher track, and as also expected, the order of the means was reversed. The highSES target in the selection condition $(M=5.62, S D=1.53$, $95 \% \mathrm{CI}=[5.16,6.07])$ was considered the most suitable, followed by the high-SES target in the educational condition $(M=5.44, S D=1.28,95 \% \mathrm{CI}=[5.00,5.88])$, the low-SES target in the educational condition $(M=5.00, S D=1.40$, $95 \% \mathrm{CI}=[4.55,5.45])$, and finally the low-SES target in the selection condition $(M=4.85, S D=1.59,95 \% \mathrm{CI}=$ $[4.41,5.30])$. The effect size of the difference between high- and low-SES targets was Cohen's $d=0.5$ in the selection condition, and Cohen's $d=0.3$ in the educational condition.

Participants' background. We also tested the effect of participants' parental education to see whether their social class had an effect on their tracking decisions. The analysis showed a significant effect of track, $F(1,149)=72.13$, $p<.001, \eta_{\mathrm{p}}^{2}=.33$, and the predicted interaction with the planned contrast, $F(1,149)=10.43, p=.002, \eta_{\mathrm{p}}^{2}=.07$. Participants' parental education did not interact with any of the variables, $F \mathrm{~s}<1$.

\section{Discussion}

The order of the means in both the lower and the higher track is congruent with our hypothesis that tracking in a selective institutional context, more than in an educational context, is associated to SES inequalities, even when achievement is kept constant. The results suggest that selection can affect the agents' behavior, shaping and even creating the difficulties/advantages encountered by students of different social class in a manner that reproduces social inequalities at school.

In the present study, we had a specific hypothesis and thus we followed the recommendation of many scholars who suggest to use theoretically focused a priori planned contrasts, for their increased power and specificity, as an 
alternative to less theoretically focused omnibus tests (e.g., interaction) when the researchers' goal is to investigate an overall pattern of means instead of several specific effects (Judd, McClelland, \& Culhane, 1995; Levin \& Neumann, 1999; Van Wesel, 2011). It should be noted, however, that some scholars favor the use of a more traditional ANOVA strategy, as some contrasts may be sensitive to effects not captured by the predicted contrast when the pattern include two or more local effects, leading to increased family-wise error rate (e.g., see the debate between Abelson, 1996; Petty, Fabrigar, Wegener, \& Priester, 1996; Rosnow \& Rosenthal, 1996). In our case, none of the residual contrasts included in the analyses of Experiment 3 specifically tested the main effect of target's SES. In other words, there is a non-negligible chance that the contrast remains significant in the presence of the main effect of SES alone. Therefore, the results of Experiment 3 should be interpreted with caution. As a robustness check, we conducted additional analyses using the $\mathrm{R}$ package "Restriktor" (http://www.restriktor.ugent.be/index.html), which tests an inequality constrained linear mean order hypothesis. We performed the analysis on the lower track, higher track, and the difference between higher and lower track. All the results confirmed a linear order of the means in the direction of our hypothesis. ${ }^{5}$

\section{General Discussion}

A meritocratic educational system, by rewarding individual performance, is supposed to circumvent group-based considerations and therefore offer every student the same opportunities. Yet, in reality, socioeconomic background remains one of the main predictors of future academic achievements in most countries (OECD, 2011). When comparing the effects of tracking between countries, reports present evidence for a link between tracking and social class inequalities in education (Brunello \& Checchi, 2007; OECD, 2011; Schütz et al., 2008). The correlational relationships examined in past work were studied experimentally in the three studies presented here, to test that selection based on tracking can paradoxically favor social class inequalities. In other words, we aimed to uncover whether the social class gap in tracking that has been observed in numerous studies could partly be a by-product of an institutional logic of selection.

The results of our first experiment confirmed our first prediction: Participants recreated the disparities observed in school when they were placed in the strategic position to actively influence pupils' prospects. These results were replicated with a sample of preservice and in-service teachers. In all experiments, no individual factors (such as participant's own social class, and years of practice as a teacher) significantly moderated this effect. Finally, the third experiment was devised to test our second hypothesis that the artificial creation of a social class gap in tracking would be at least partly explained by the institutional function of selection. The results are in line with this interpretation and seem to indicate that the function of selection of the educational system is linked to the creation of social class inequalities at school.

\section{Contributions}

This research sheds light on a new mechanism informing the debate over the link between tracking policies and social inequalities: selective educational contexts can lead agents to produce biased academic decisions. Until now, this debate focused primarily on the cost versus benefits for students to be in classrooms structured around the students' academic potential, presuming that pupils' achievement level was adequately assessed by the agents of the education system. Yet, the results of our research provide evidence of the contrary. Regardless of their actual merit, lower SES pupils were considered more suited for a lower track and less suited for a higher track comparatively to their higher SES counterparts with the same grades. Proponents of tracking policies generally suggest that having differentiated curricula or classes based on the students' level of achievement can serve the improvement of learning for all students (Hallinan, 1994). But if, as we propose, teacher's biases might be prompted by selective educational contexts, then tracking policies could instead lead teachers to artificially create academic differences among students. More generally, the implications of our research suggest that efforts toward raising lower social class students' performance may not be sufficient to combat social class inequalities at school. Attention should also be devoted to the intent underlying institutional practices. Particularly, in a context where schools are often under political pressure to provide external proof of their productivity and of their high standards, increasing selection can seem a reasonable solution to achieve excellence. In light of our results, we would suggest to carefully consider the consequences of such strategies, as drawbacks on equality of opportunity may outweigh the potential benefits.

Moreover, the present research builds upon a growing literature in social psychology that has been directed toward examining cultural and structural factors involved in the perpetuation of the social class achievement gap (e.g., Adams et al., 2008; Croizet et al., 2017; Jury et al., 2017; Kraus \& Park, 2017). These studies have consistently demonstrated the importance of looking into the role of institutional contexts to fully understand the reasons why low-SES students or high-SES students are more susceptible to fail/succeed at school. However, by focusing on student's contextual ability to perform, previous studies did not directly address how performance could also be constructed by evaluators and, by extension, the institution. In this research, we went beyond individual performance by investigating the structural obstacles that contribute to actively exclude low social class pupils from higher education. Our research provides initial empirical support to the validity of this approach, as the results 
were consistent with the hypothesis that structural factors, such as the intended function of educational institutions, are related to the creation of social class inequalities at school.

Increased societal inequality has been identified as a social problem requiring urgent attention by the World Economic Forum report on the 2015 Global Agenda. In fact, their report also indicates that improved education is considered to be one of the top solutions to resolve the issue of deepening inequalities (World Economic Forum, 2015). A major contribution of our research is the experimental investigation of one specific structural factor in the educational system that could hinder the potentially beneficial effect of the democratization of the educational system. The present results provide preliminary support to the hypothesis that the education system may encourage the reproduction of social class inequalities because its selective structure prompts evaluators to make decisions that hinder the chances of success of lower SES students and favor those of higher SES students. In this respect, our findings provide initial experimental evidence supporting a long-standing line of research that has linked social class inequalities to the functioning of the educational system (Bourdieu \& Passeron, 1990; Bowles \& Gintis, 1976; Marks, Cresswell, \& Ainley, 2006; Oakes, 1985; Van de Werfhorst \& Mijs, 2010). This research used experimental designs to study the structural causes of social class discrimination in tracking. To the best of our knowledge, it is the first to investigate the causal relationship between the function of the school system and unequal treatment of students of different social classes by agents of the system in the case of tracking.

\section{Limitations and Conclusion}

Some limitations should be mentioned. First, the aim of our research was to investigate a structural mechanism (i.e., institutional function) to examine the social class gap in tracking. As it was beyond the scope of this research, the results did not address the individual-level mechanisms at stake in this specific phenomenon. Further research could build on our conclusions to examine how selective institutional contexts affect institutional agents' specific psychological processes. Second, Experiment 1 revealed an interaction between SES and gender. Although unexpected, this result is consistent with prior literature describing opposite academic gender stereotypes of teenagers, which could lead to social class disadvantages targeting boys more than girls. However, as this pattern of result is not replicated in Experiment 3, we think that further intersectional research is needed to test the robustness of this effect. Third, results of Experiment 3 provide initial support for the role of institutional function, but future research should use larger samples to provide a direct replicative test of our hypothesis.

In sum, the SES achievement gap due to selection practices such as tracking may not entirely result from the lower ability of low-SES students or from some particularly prejudiced teachers. It appears that the very principle of institutional selection could play a central role in the reproduction of social inequalities observed in the use of tracking. An OECD (2011) report suggests that tracking policies may have a general negative impact on equal opportunity for all in education and propose to delay selection to reduce its consequences. Our findings provide convergent experimental evidence in favor of this position by highlighting the paradoxical effects of selection-based practices on equality of treatment for students.

\section{Authors' Note}

Anatolia Batruch is now at University of Amsterdam, Amsterdam, The Netherlands. Frédérique Autin is now at Université de Poitiers, CeRCA, Poitiers, France.

\section{Acknowledgments}

We wish to express our gratitude to Jean-Philippe Antonietti, Benoît Dompnier, and Nicolas Sommet for invaluable comments on an earlier draft, and Philemon Griesmar, Vincent Pillaud, Philippe Sperisen and Sophia Stark for help in data collection.

\section{Declaration of Conflicting Interests}

The author(s) declared no potential conflicts of interest with respect to the research, authorship, and/or publication of this article.

\section{Funding}

The author(s) disclosed receipt of the following financial support for the research, authorship, and/or publication of this article: This work was supported by the Swiss National Science Foundation (grant CRSII1_141872), and was part of Anatolia Batruch's doctoral dissertation at University of Lausanne under the supervision of Fabrizio Butera.

\section{Notes}

1. The booklet included a questionnaire measuring the perceived success factors at school. These measures are not relevant for the hypothesis presented here, and we did not report the results, but they are available upon request.

2. They were also asked to answer what the school's headmaster would have answered. As the results are identical to those of the other measures, and as we did not include this measure in the other studies, we did not report the results. They are available upon request.

3. As in Experiment 1, participants also answered what they think other teachers and the headmaster would decide. Results about the decisions attributed to other teachers are presented in Supplemental Material and results about the headmaster are available upon request.

4. As in Experiments 1 and 2, see Supplemental Material for the decisions attributed to other teachers and results about the headmaster are available upon request.

5. The results provide affirmative evidence in favor of a linearly constrained means hypothesis. Specifically, Hypothesis test Type B tests the null hypothesis of the means linearity versus the alternative hypothesis of at least one violation of the linearity. 
Hypothesis test Type A tests a null hypothesis of equality of means versus the alternative of a least one violation of the equality of means. For the lower track, Hypothesis test Type B is not rejected, $F_{(0,1,2,3 ; 156)}^{\mathrm{B}}=0, p=1$, in favor of the unconstrained hypothesis (i.e., best fitting hypothesis). This means that the constraints are in line with the data. Hypothesis test Type A is rejected in favor of the order-constrained hypothesis, $F_{(0,1,2,3 ; 156)}^{\mathrm{A}}$ $=12.03, p=.001$. Similarly for the opposite pattern in the higher track, Hypothesis test Type $\mathrm{B}$ is not rejected, $F_{(0,1,2,3 ; 156)}^{\mathrm{B}}$ $=0, p=1$, in favor of the unconstrained hypothesis (i.e., best fitting hypothesis). Hypothesis test Type A is rejected in favor of the order-constrained hypothesis, $F_{(0,1,2,3 ; 156)}^{\mathrm{A}}=7.52, p=.012$.

\section{Supplemental Material}

Supplemental material is available online with this article.

\section{References}

Abelson, R. P. (1996). Vulnerability of contrast tests to simpler interpretations: An addendum to Rosnow and Rosenthal. Psychological Science, 7, 242-246. doi:10.1111/j.1467-9280.1996.tb00367.x

Adams, G., Biernat, M., Branscombe, N. R., Crandall, C. S., \& Wrightsman, L. S. (2008). Beyond prejudice: Toward a sociocultural psychology of racism and oppression. In G. Adams, M. Biernat, N. R. Branscombe, C. S. Crandall, \& L. S. Wrightsman (Eds.), Commemorating Brown: The social psychology of racism and discrimination (pp. 215-246). Washington, DC: American Psychological Association. doi:10.1037/11681-012

Autin, F., Batruch, A., \& Butera, F. (2015). Social justice in education: How the function of selection in educational institutions predicts support for (non)egalitarian assessment practices. Frontiers in Psychology, 6, Article, 707. doi:10.3389/ fpsyg.2015.00707

Autin, F., Batruch, A., \& Butera, F. (in press). The function of selection of assessment leads evaluators to artificially create the social class achievement gap. Journal of Educational Psychology.

Batruch, A., Autin, F., \& Butera, F. (2017). Re-establishing the social-class order: Restorative reactions against high-achieving, low-SES pupils. Journal of Social Issues, 73, 42-60. doi: $10.1111 /$ josi.12203

Bennett, J. E., \& Sekaquaptewa, D. (2014). Setting an egalitarian social norm in the classroom: Improving attitudes towards diversity among male engineering students. Social Psychology of Education, 17, 343-355. doi:10.1007/s11218-014-9253-y

Betts, J. R., \& Shkolnik, J. L. (2000). The effects of ability grouping on student achievement and resource allocation in secondary schools. Economics of Education Review, 19, 1-15. doi:10.1016/S0272-7757(98)00044-2

Bol, T., \& Van de Werfhorst, H. G. (2013). Educational systems and the trade-off between labor market allocation and equality of educational opportunity. Comparative Education Review, 57, 285-308. doi:10.1086/669122

Bol, T., Witschge, J., Van de Werfhorst, H. G., \& Dronkers, J. (2014). Curricular tracking and central examinations: Counterbalancing the impact of social background on student achievement in 36 countries. Social Forces, 92, 1545-1572. doi: $10.1093 /$ sf $/$ sou003
Bourdieu, P., \& Passeron, J. C. (1990). Reproduction in education, society and culture. London, England: SAGE.

Bowles, S., \& Gintis, H. (1976). Schooling in capitalist America. New York, NY: Basic Books.

Brauer, M., \& McClelland, G. (2005). L'utilisation des contrastes dans l'analyse des données: Comment tester les hypothèses spécifiques dans la recherche en psychologie? [Using contrasts in data analysis: How to test specific hypotheses in psychological research]. L'année Psychologique, 105, 273-305. doi:10.3406/psy.2005.29696

Brunello, G., \& Checchi, D. (2007). Does school tracking affect equality of opportunity? New international evidence. Economic Policy, 22, 782-861. doi:10.1016/j.econedurev.2004.09.001

Castilla, E. J., \& Benard, S. (2010). The paradox of meritocracy in organizations. Administrative Science Quarterly, 55, 543-576. doi:10.2189/asqu.2010.55.4.543

Chmielewski, A. K. (2014). An international comparison of achievement inequality in within- and between-school tracking systems. American Journal of Education, 120, 293-324. doi:10.1086/675529

Coulmont, B. (2011). Sociologie des prénoms [Sociology of first names]. Paris, France: La Découverte.

Croizet, J.-C., \& Claire, T. (1998). Extending the concept of stereotype threat to social class: The intellectual underperformance of students from low socioeconomic backgrounds. Personality and Social Psychology Bulletin, 24, 588-594. doi:10.1177/0146167298246003

Croizet, J.-C., Goudeau, S., Marot, M., \& Millet, M. (2017). How do educational contexts contribute to the social class achievement gap: Documenting symbolic violence from a social psychological point of view. Current Opinion in Psychology, 18, 105-110. doi:10.1016/j.copsyc.2017.08.025

Croizet, J.-C., \& Millet, M. (2012). Social class and test performance: From stereotype threat to symbolic violence and vice versa. In M. Inzlicht \& T. Schmader (Eds.), Stereotype threat: Theory, process, and application (pp. 188-201). New York, NY: Oxford University Press.

Darnon, C., Dompnier, B., Delmas, F., Pulfrey, C., \& Butera, F. (2009). Achievement goal promotion at university: Social desirability and social utility of mastery and performance goals. Journal of Personality and Social Psychology, 96, 119134. doi:10.1037/a0012824

Darnon, C., Smeding, A., \& Redersdorff, S. (2018). Belief in school meritocracy as an ideological barrier to the promotion of equality. European Journal of Social Psychology, 48, 523-534.

DiTomaso, N. (2015). Racism and discrimination versus advantage and favoritism: Bias for versus bias against. Research in Organizational Behavior, 35, 57-77. doi:10.1016/j. riob.2015.10.001

Dornbusch, S. M., Glasgow, K. L., \& Lin, I. C. (1996). The social structure of schooling. Annual Review of Psychology, 47, 401429. doi:10.1146/annurev.psych.47.1.401

Dusek, J. B., \& Joseph, G. (1983). The bases of teacher expectancies: A meta-analysis. Journal of Educational Psychology, 75, 327-346. doi:10.1037/0022-0663.75.3.327

Faniko, K., Lorenzi-Cioldi, F., Buschini, F., \& Chatard, A. (2012). The influence of education on attitudes toward affirmative action: The role of the policy's strength. Journal of 
Applied Social Psychology, 42, 387-413. doi:10.1111/j.15591816.2011.00892.x

Farkas, G. (2003). Racial disparities and discrimination in education: What do we know, how do we know it, and what do we need to know? Teachers College Record, 105, 1119-1146. doi:10.1111/1467-9620.00279

Faul, F., Erdfelder, E., Buchner, A., \& Lang, A.-G. (2009). Statistical power analyses using $\mathrm{G}^{*}$ Power 3.1: Tests for correlation and regression analyses. Behavior Research Methods, 41, 1149-1160. doi:10.3758/BRM.41.4.1149

Felouzis, G., \& Charmillot, S. (2013). School tracking and educational inequality: A comparison of 12 education systems in Switzerland. Comparative Education, 49, 181-205. doi:10.108 0/03050068.2012.706032

Fennema, E., Peterson, P. L., Carpenter, T. P., \& Lubinski, C. A. (1990). Teachers' attributions and beliefs about girls, boys, and mathematics. Educational Studies in Mathematics, 21, 55-69. doi:10.1007/BF00311015

Glock, S., Krolak-Schwerdt, S., Klapproth, F., \& Böhmer, M. (2013). Beyond judgment bias: How students' ethnicity and academic profile consistency influence teachers' tracking judgments. Social Psychology of Education, 16, 555-573. doi:10.1007/s11218-013-9227-5

Goudeau, S., Autin, F., \& Croizet, J. C. (2017). Etudier, mesurer et manipuler la classe sociale en psychologie sociale: Approches économiques, symboliques et culturelles [Studying, measuring and manipulating social class in social psychology: Economic, symbolic and cultural approaches]. International Review of Social Psychology, 30, 1-19. doi:10.5334/irsp.52

Goudeau, S., \& Croizet, J. C. (2017). Hidden advantages and disadvantages of social class: How classroom settings reproduce social inequality by staging unfair comparison. Psychological Science, 28, 162-170. doi:10.1177/0956797616676600

Hallinan, M. T. (1994). Tracking: From theory to practice. Sociology of Education, 67, 79-84. doi:10.2307/2112697

Hanushek, E., \& Wößmann, L. (2006). Does educational tracking affect performance and inequality? Differences-in-differences evidence across countries. The Economic Journal, 116, C63C76. doi:10.1111/j.1468-0297.2006.01076.x

Hartley, B. L., \& Sutton, R. M. (2013). A stereotype threat account of boys' academic underachievement. Child Development, 84 , 1716-1733. doi:10.1111/cdev.12079

Hattie, J. A. C. (2002). Classroom composition and peer effects. International Journal of Educational Research, 37, 449-481. doi:10.1016/S0883-0355(03)00015-6

Heyder, A., \& Kessels, U. (2015). Do teachers equate male and masculine with lower academic engagement? How students' gender enactment triggers gender stereotypes at school. Social Psychology of Education, 18, 467-485. doi:10.1007/s11218-015-9303-0

Hinnerich, B. T., Höglin, E., \& Johannesson, M.(2015). Discrimination against students with foreign backgrounds: Evidence from grading in Swedish public high schools. Education Economics, 23, 660-676. doi:10.1080/09645292.2014.899562

Huang, M. H. (2009). Classroom homogeneity and the distribution of student math performance: A country-level fixed-effects analysis. Social Science Research, 38, 781-791. doi:10.1016/j. ssresearch.2009.05.001

Jones, S., \& Myhill, D. (2004). "Troublesome boys" and "compliant girls": Gender identity and perceptions of achievement and underachievement. British Journal of Sociology of Education, 25, 547-561. doi:10.1080/0142569042000252044

Judd, C. M., \& McClelland, G. H. (1989). Data analysis: A model comparison approach. San Diego, CA: Harcourt Brace Jovanovich.

Judd, C. M., McClelland, G. H., \& Culhane, S. E. (1995). Data analysis: Continuing issues in the everyday analysis of psychological data. Annual Review of Psychology, 46, 433-465. doi:10.1146/ annurev.ps.46.020195.002245

Judd, C. M., McClelland, G. H., \& Ryan, C. S. (2011). Data analysis: A model comparison approach. Oxford, UK: Routledge.

Jury, M., Smeding, A., \& Darnon, C. (2015). First-generation students' underperformance at university: The impact of the function of selection. Frontiers in Psychology, 6, Article, 710. doi:10.3389/fpsyg.2015.00710

Jury, M., Smeding, A., Stephens, N. M., Nelson, J. E., Aelenei, C., \& Darnon, C. (2017). The experience of low-SES students in higher education: Psychological barriers to success and interventions to reduce social-class inequality. Journal of Social Issues, 73, 23-41. doi:10.1111/josi.12202

Kerckhoff, A. C. (1986). Effects of ability grouping in British secondary schools. American Sociological Review, 51, 842-858.

Kiss, D. (2013). Are immigrants and girls graded worse? Results of a matching approach. Education Economics, 21, 447-463. doi: 10.1080/09645292.2011.585019

Konan, P. N., Chatard, A., Selimbegović, L., \& Mugny, G. (2010). Cultural diversity in the classroom and its effects on academic performance. Social Psychology, 41, 230-237. doi:10.1027/1864-9335/a000031

Kraus, M. W., \& Park, J. W. (2017). The structural dynamics of social class. Current Opinion in Psychology, 18, 55-60. doi:10.1016/j.copsyc.2017.07.029

Levin, J. R., \& Neumann, E. (1999). Testing for predicted patterns: When interest in the whole is greater than in some of its parts. Psychological Methods, 4, 44-57. doi:10.1037/1082989X.4.1.44

Marks, G. N., Cresswell, J., \& Ainley, J. (2006). Explaining socioeconomic inequalities in student achievement: The role of home and school factors. Educational Research and Evaluation, 12, 105-128. doi:10.1080/13803610600587040

Markus, H. R., \& Stephens, N. M. (2017). Editorial overview: The psychological and behavioral consequences of inequality and social class: A theoretical integration. Current Opinion in Psychology, 18, 4-12. doi:10.1016/j.copsyc.2017.11.001

Oakes, J. (1985). Keeping track: How schools structure inequality. New Haven, CT: Yale University Press.

Organisation for Economic Co-operation and Development. (2011). Equity and quality in education-supporting disadvantaged students and schools. Paris, France: Author. doi:10.1787/9789264130852-en

Organisation for Economic Co-operation and Development. (2013). PISA 2012 results: What makes schools successful? Resources, policies and practices (volume IV). Paris, France: Author.

Petty, R. E., Fabrigar, L. R., Wegener, D. T., \& Priester, J. R. (1996). Understanding data when interactions are present or hypothesized. Psychological Science, 7, 247-252. doi:10.1111/j.1467-9280.1996.tb00368.x

Quillian, L., Pager, D., Hexel, O., \& Midtbøen, A. H. (2017). Meta-analysis of field experiments shows no change in racial 
discrimination in hiring over time. Proceedings of the National Academy of Sciences of the United States of America, 114, 10870-10875. doi:10.1073/pnas.1706255114

Riegle-Crumb, C., \& Humphries, M. (2012). Exploring bias in math teachers' perceptions of students' ability by gender and race/ethnicity. Gender \& Society, 26, 290-322. doi: $10.1177 / 0891243211434614$

Rosnow, R. L., \& Rosenthal, R. (1996). Contrasts and interactions redux: Five easy pieces. Psychological Science, 7, 253-257. doi: 10.1111/j.1467-9280.1996.tb00369

Sabbagh, C., Resh, N., Mor, M., \& Vanhuysse, P. (2006). Spheres of justice within schools: Reflections and evidence on the distribution of educational goods. Social Psychology of Education, 9, 97-118. doi:10.1007/s11218-005-3319-9

Schütz, G., Ursprung, H. W., \& Wößmann, L. (2008). Education policy and equality of opportunity. Kyklos, 61, 279-308. doi:10.1111/j.1467-6435.2008.00402.x

Sirin, S. R. (2005). Socioeconomic status and academic achievement: A meta-analytic review of research. Review of Educational Research, 75, 417-453. doi:10.3102/00346543075003417

Smeding, A., Darnon, C., Souchal, C., Toczeck-Capelle, M. C., \& Butera, F. (2013). Reducing the socio-economic status achievement gap at university by promoting mastery-oriented assessment. PLoS ONE, 8(8), e71678. doi:10.1371/journal. pone. 0071678

Snibbe, A. C., \& Markus, H. R. (2005). You can't always get what you want: Educational attainment, agency, and choice.
Journal of Personality and Social Psychology, 88, 703-720. doi:10.1037/0022-3514.88.4.703

Son Hing, L. S., Bobocel, D. R., \& Zanna, M. P. (2002). Meritocracy and opposition to affirmative action: Making concessions in the face of discrimination. Journal of Personality and Social Psychology, 83, 493-509. doi:10.1037//0022-3514.83.3.493

Son Hing, L. S., Bobocel, D. R., Zanna, M. P., Garcia, D. M., Gee, S. S., \& Orazietti, K. (2011). The merit of meritocracy. Journal of Personality and Social Psychology, 101, 433-450. doi:10.1037/a0024618

Stephens, N. M., Fryberg, S. A., Markus, H. R., Johnson, C. S., \& Covarrubias, R. (2012). Unseen disadvantage: How American universities' focus on independence undermines the academic performance of first-generation college students. Journal of Personality and Social Psychology, 102, 1178-1197. doi: $10.1037 / \mathrm{a} 0027143$

World Economic Forum (2015). The Outlook on the Global Agenda 2015. Geneva: World Economic Forum. Retrieved January 15, 2018, from http://reports.weforum.org/outlook-globalagenda-2015/

Van de Werfhorst, H. G., \& Mijs, J. J. B. (2010). Achievement inequality and the institutional structure of educational systems: A comparative perspective. Annual Review of Sociology, 36, 407-428. doi:10.1146/annurev.soc.012809.102538

Van Wesel, F. (2011). Priors \& prejudice: Using existing knowledge in social science research (Doctoral thesis). Utrecht University, The Netherlands. 